\title{
LA INDUSTRIA LÍTICA TALLADA DEL NEOLÍTICO ANTIGUO EN LA VERTIENTE MEDITERRÁNEA DE LA PENÍNSULA IBÉRICA*
}

\author{
JAVIER FORTEA PÉREZ \\ Universidad de Oviedo \\ BERNARDO MARTÍ OLIVER \\ JOAQUIM JUAN CABANILLES \\ Servicio de Investigación Prehistórica. Valencia
}

\begin{abstract}
En relación con el problema de la dualidad cultural existente en los inicios del Neolítico en la fachada mediterránea peninsular, los estudios de industria lítica realizados desde la parcela estrictamente neolítica han aportado nuevas precisiones a la problemática planteada. La industria de piedra tallada, como elemento más común a los distintos grupos implicados, ha devenido un buen factor de comparación y de ayuda para la articulación de las dos tradiciones constatadas: la epipaleolítica geométrica de la facies Cocina y la Neolítica pura tipo Or o Sarsa.

Le problème de la dualité culturelle existant sur le littoral méditerranéen de la péninsule Ibérique au début du Ve millénaire a. C. connaît de nouvelles précisions grâce aux études de l'industrie lithique réalisées à partir du domaine strictement néolithique. L'industrie de la pierre taillée, perçue comme l'élément le plus comun aux différents groupes impliqués, est devenu un repère et un facteur de comparäison remarquable pour l'articulation des deux traditions constatées: Ia tradition épipaléolithique géométrique du faciès de Cocina et la pure tradition néolithique du type d'Or ou Sarsa.
\end{abstract}

\section{EL PANORAMA CULTURAL}

Desde los inicios del $7 .^{\circ}$ milenio B. P. la vertiente mediterránea de la Península Ibérica conoce dos comunidades diferenciables arqueológicamente: la neolítica, caracterizada por la cerámica impresa cardial, que inaugura el Neolítico antiguo, y la representada por los momentos finales del Epipaleolítico geométrico de facies Cocina, que entrará en contacto con los neolíticos cardiales, recibirá

(*) El presente trabajo es la comunicación presentada por los autores al simposio internacional Chipped Stone Industries of The Early Farming Cultures in Europe, celebrado en Cracovia (Polonia) en octubre de 1985, con el título «L'industrie lithique du Néolithique ancien dans le versant méditerranéen de la Péninsule Ibérique». paulatinamente algunos de sus elementos y perdurará paralelamente.

Puede afirmarse que el impulso genuino y responsable de la implantación del Neolítico es el aportado por las gentes cardiales. Los epipaleolíticos, según su registro arqueológico, jugaron un papel más pasivo en el contacto cultural: los diferentes yacimientos indican aquí la sola adopción de la cerámica, allá la de ésta y unos pocos animales domésticos. Pero aunque aquellos epipaleolíticos sean los hogares marginales del proceso de la neolitización, no dejan de ser una parte importante de su dispositivo, porque desde una perspectiva de tiempo largo, contribuyeron a su definitiva implantación.

Sin embargo, la bibliografía actual ha pretendido complejificar este panorama cultural. Así, han sido propuestos un Neolítico precerámico; un Pro- 
toneolítico, ya en el sentido de vaga etapa transicional, ya en el de horizonte de cerámicas lisas anterior al impreso cardial; o un Neolítico de cerámicas incisas igualmente anterior al cardial. Recientemente hemos presentado una revisión crítica indicando la gratuidad en unos casos, o la inconsistencia argumental en otros, de aquellos Neolíticos diferentes al impreso cardial como primera etapa de la neolitización (MARTÍ et alii, 1987; FORTEA y MARTÍ, 1984-85). Con respecto al Epipaleolítico se señalaron también las perduraciones del Complejo Microlaminar, de raíz aziloide y anterior al Geométrico, que en zonas muy concretas habría entrado en contacto sin porvenir con los cardiales, $o$, también, el papel de sustrato epipaleolítico final, sobre el que se instalaría el Neolítico antiguo, que pudieron jugar industrias de poca cualificación técnica y mínimo polimorfismo tipológico, ya que muescas y denticulaciones y raspadores son los grupos dominantes. En nuestra opinión, la reciente investigación no ha aportado más datos referentes a la perduración del Epipaleolítico microlaminar, y en lo que concierne a aquellas industrias de nulo politipismo, parecen facies especializadas cuyo problema principal es el cronológico (FORTEA et alii, 1987; FORTEA Y MARTÍ, 1984-85).

Por el contrario, la estratigrafía comparada ofrece un número suficiente de datos coincidentes y mutuamente explicables para afirmar que desde el inicio del $7 .^{\circ}$ milenio B. P. neolíticos cardiales y epipaleolíticos geométricos neolitizados son los grupos más significativos. Entre ellos existiría un gradiente de situaciones intermedias difíciles de valorar y, quizá, otras facies que podrán clarificarse una vez que el registro arqueológico general nos sea mejor conocido.

Se analizarán las características de la industria lítica del Neolítico antiguo para compararla después con la epipaleolítica y ver cómo sus respectivas tradiciones culturales informan a buen número de yacimientos del área en estudio.

\section{LA INDUSTRIA LÍTICA DEL NEOLÍTICO ANTIGUO}

La industria lítica tallada del Neolítico Antiguo de la zona Oriental de la Península Ibérica, en contraposición con lo que ocurre normalmente en otras áreas, es bastante bien conocida en el momento actual gracias a los diferentes trabajos de conjunto -0 a las especificas valoraciones en este campo líticode que han sido objeto dos de sus yacimientos más representativos, la Cova de l'Or (Beniarrés, Alacant) y la Cova de la Sarsa (Bocairent, València).

Por la información proporcionada en este terreno industrial señalaríamos, para el caso de l'Or, las primeras anotaciones de Fletcher (1962) y los más detenidos análisis de Fortea (1973, 406-413), Martí (1977 y 1983) y Martí et alii (1980); para el caso de la Sarsa, los primeros inventarios de San Valero (1950) y las posteriores valoraciones de Asquerino (1978). Como estudios más centrados en las particularidades del utillaje y la problemática lítica de ambos yacimientos, considerados conjuntamente, reseñaríamos los realizados recientemente por JuanCabanilles (1983 y 1984) y Martí y Juan-Cabanilles (1984).

En estos trabajos citados nos basaremos a la hora de exponer las características esenciales de la industria de talla del Neolítico Antiguo cardial, subrayando que yacimientos como Or o Sarsa ejemplifican ampliamente, por la cantidad de efectivos y por la representación formal, el hecho lítico de esta etapa cultural en el marco del Mediterráneo peninsular español.

\subsection{MATERIA PRIMA Y TECNOLOGÍA BÁSICA}

La materia prima utilizada en el Neolítico cardial para su industria de talla es exclusivamente el sílex. Se trata generalmente de un sílex melado de buena calidad, seleccionado a partir de guijarros, nódulos y bloques de mediano y pequeño tamaño.

Los productos básicos de esta industria son láminas y laminitas acordes dimensionalmente con el tamaño de los nódulos y, lógicamente, con el de los núcleos preparados de extracción; 'sus patrones tipométricos oscilan entre 1 y 1,5 centímetros y espesores entre 3 y 4 centímetros de longitud media, anchuras comprendidas ente 1 y 1,5 centímetros y espesores entre 0,20 y 0,35 centímetros, para el caso concreto de l'Or (JUAN-CABANILLES, 1984), siendo estas dimensiones coincidentes con lo que revela la Sarsa (ASQUERINO, 1978).

Láminas y laminitas procederían en mayor medida de núcleos prismáticos y piramidales, estos últimos a veces de muy reducido tamaño y en relación estrecha con la obtención de los productos menores; con todo, no faltan núcleos globulares y 


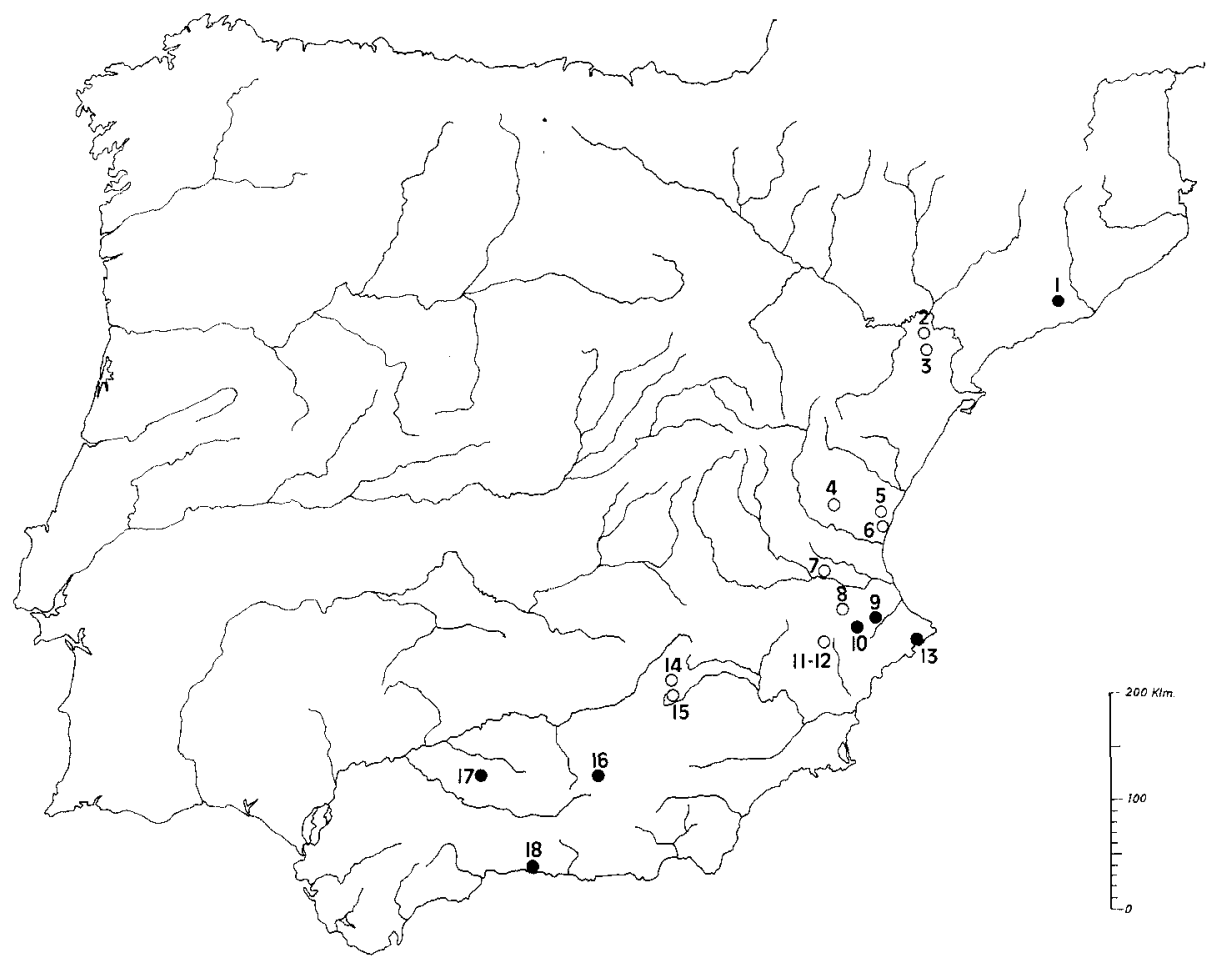

Fig. 1.- Relación de los yacimientos mencionados en el texto. $\bigcirc$ Tradición epipaleolítica.

Tradición neolítica. N. ${ }^{\circ}$ 1. Les Guixeres. N. ${ }^{\circ}$ 2. Costalena. N. ${ }^{\circ}$ 3. Botiqueria dels Moros. N. ${ }^{\circ}$ 4. Llatas. N. ${ }^{\circ}$ 5. Can Ballester. N. ${ }^{\circ} 6$. Estany Gran. N. ${ }^{\circ} 7$. Cocina. $^{\circ}$ N. ${ }^{\circ}$. Albufera de Anna. N. ${ }^{\circ}$ 9. Or. N. ${ }^{\circ}$ 10. Sarsa. N. ${ }^{\circ} 11-12$. Casa de Lara y Arenal de la Virgen. N. ${ }^{\circ} 13$. Cendres. N. ${ }^{\circ} 14$. Valdecuevas. N. ${ }^{\circ}$ 15. Nacimiento. N. ${ }^{\circ}$ 16. Carigüela. N. ${ }^{\circ} 17$. Murciélagos. N. ${ }^{\circ} 18$. Nerja.

poliédricos en avanzado estado de uso (prácticamente agotados), los cuales deben haber proporcionado una fracción importante del constatable stock de lascas que, sin alcanzar las cotas de los productos laminares como soportes de útiles, sí que revisten cierta significación como parte del utillaje utilizado en bruto o someramente retocado, tal como veremos en su correspondiente epígrafe.

Así pues, y en sus rasgos más generales, la tecnología básica cardial, orientada principalmente — como hemos visto - a la obtención de productos laminares, denota lo que convendríamos en llamar un primer estilo neolítico de talla; estilo que, en su orientación específica, se enmarcaría entre la producción laminar epipaleolítica propia de los grupos microlaminares y geométricos caracterizados por Fortea (1973), con patrones métricos más reducidos y mayor irregularidad morfológica de los soportes, y la excelente factura de la talla del Neolítico finalEneolítico, reflejada en los materiales de algunos poblados y en los ajuares recuperados en las abundantes cuevas sepulcrales de la zona.

\subsection{TECNOLOGÍA ESPECIFICA Y TIPOLOGÍA}

En el campo de la tecnología específica, es decir, la serie de gestos encaminados a la conformación definitiva de los útiles, destacaríamos en la industria cardial el evidente y sistemático acortamiento de los soportes laminares mediante fracturas voluntarias, debidas normalmente a flexión o percusión. Esta solución técnica nos sitúa ante una producción estereotipada de piezas-soporte, en bastantes casos dispuestas para ser utilizadas directamente, sin modificaciones secundarias; además, la eliminación de bulbos y extremidades distales arqueadas parece responder a una finalidad técnica precisa, relacionada sin duda con el enmangue individual o colectivo de las piezas; este hecho lo deja entrever incontestablemente el análisis formal del utillaje y la orientación tecno-funcional básica del mismo. Sobre ello volveremos en otros momentos de la exposición.

Atendiendo en líneas generales a las características formales definidas estrictamente por el reto- 

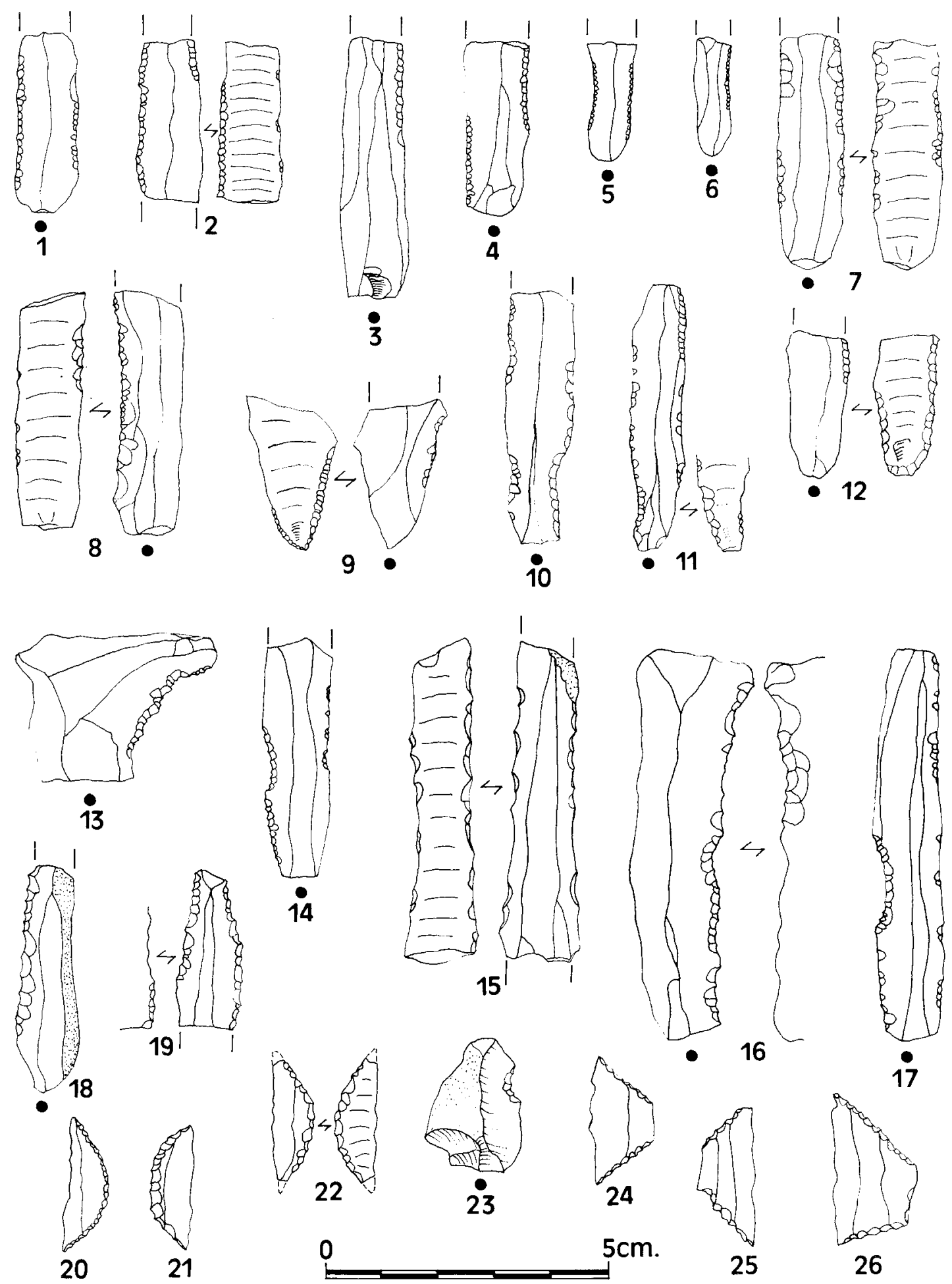

17

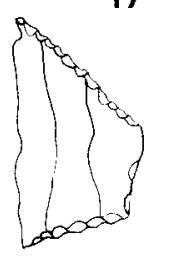

26

Fig. 2.-Utillaje en sílex neolítico (Cova de l'Or y Cova de la Sarsa). N. ${ }^{\circ} 1$ a 4 : láminas y laminitas con retoques marginales. N. 5 y 6: L. y l. con retoques muy marginales. N. ${ }^{\circ} 7$ y $8:$ L. y 1 . con retoques irregulares. N. ${ }^{\circ} 12:$ L. con borde abatido. N. ${ }^{\circ} 9$ a 11 : L. y l. con escotadura o preparación terminal. N. ${ }^{\circ} 14$ a 19: L. y 1 . con muesca o denticulación. N. ${ }^{\circ} 13:$ lasca con denticulación. N. ${ }^{\circ} 23$ : lasca con muesca. N. ${ }^{\circ} 20$ a 22 : segmentos. N. ${ }^{\circ} 24$ a 26 : trapecios. 
que, una parte del utillaje cardial (el utillaje retocado) puede organizarse en las siguientes categorías tipológicas: Láminas y Laminitas retocadas, Muescas y Denticulados, Geométricos, Truncaduras, Perforadores y Taladros y Piezas Diversas. El orden de exposición que seguimos responde a la generalizada constatación de efectivos numéricos particulares y a su disposición en una secuencia decreciente.

Las láminas y laminitas retocadas suelen ser predominantes. Los retoques son por regla general simples o de tendencia abrupta, totales o parciales, dominando estos últimos en disposición unilateral; su localización suele ser marginal o muy marginal, recordando en ciertas piezas al retouche de Fère (G.E.E.M., 1969). También se dan retoques irregulares de disposición arbitraria, o retoques más abruptos que a veces pueden formar dorso. Otras veces su delineación es cóncava, localizada proximalmente y formando escotadura. Todos estos caracteres del retoque permiten establecer subdivisiones formales dentro de este primer grupo tipológico. Su porcentaje puede alcanzar el $30 \%$ del utillaje retocado.

Siguen en importancia las muescas y denticula$d o s$, con índices que pueden oscilar entre el $20 \mathrm{y}$ el $30 \%$. Se constatan preferentemente sobre soportes laminares, como es normal a la mayor parte del utillaje cardial. La diferencia de estas piezas con las del grupo anterior radicaría muchas veces en la sola delineación del retoque. En la mayoría de casos la denticulación es irregular y de localización marginal; en ocasiones, aunque poco frecuentes, dada cuerta regularidad en el desarrollo de la denticulación, podrían definirse piezas del tipo «sierra» (TIXIER, 1963, 124).

Los geométricos ofrecen destacados desfases porcentuales y de representación formal según los yacimientos. En la Cova de l'Or alcanzan el $20 \%$ del utillaje retocado, mientras que en la Sarsa no pasan del $6 \%$. Una particularidad importante es la de que la técnica del microburil no interviene ahora en la elaboración de estas piezas. Con toda probabilidad la técnica empleada se reduzca a la fractura por flexión o percusión del soporte inicial y al retoque posterior de los lados fracturados. Las formas documentadas son trapecios, segmentos y triángulos (estos últimos, presentes en l'Or, faltan en la Sarsa). Dominan claramente los trapecios (pueden constituir el $80 \%$ del grupo) con abundantes variaciones formales; siguen los segmentos (sobre el $13 \%$ en l'Or), mientras que los triángulos son escasos y morfológicamente bastante atípicos. El retoque predominante en todas estas piezas es el abrupto, tanto directo como alterno, siendo raro el de dirección inversa; la técnica del doble bisel (o Hélouan) se encuentra documentada, aunque en una proporción bastante escasa y localizada estrictamente en los segmentos.

Las truncaduras constituyen siempre una categoría menor, con un índice centrado en el 6\%. Morfológicamente preponderan las truncaduras oblicuas sobre las rectas, siendo escasas las dobles. Hay que señalar el carácter microlítico de alguna de ellas, conformando piezas trapezoidales donde una línea truncada se opone a una fractura no retocada.

También categorías menores son los taladros y perforadores, que conjuntamente pueden ofrecer porcentajes entre el $5 \%$ y el $7 \%$, aunque en el caso de los primeros su significación cultural está por encima de su representación. Los taladros son entendidos en el sentido propuesto por Cauvin (1968, 154), y su preponderancia es notable sobre los perforadores en sentido estricto, basculando particularmente entre el $4 \%$ y el $6,5 \%$ del total del utillaje retocado; se encuentran fabricados también siempre sobre productos laminares. El retoque de los taladros, normalmente abrupto o de tendencia abrupta, puede ser tanto directo como alterno, siendo muy raras las piezas con retoque inverso o bifacial.

Por último, piezas no encuadrables en los anteriores grupos tipológicos serían las lascas con algún retoque, en ocasiones cercanas al tipo raedera, así como también otros escasos útiles de substrato o útiles comunes: raspadores, cuchillos de dorso (natural o por retoque), productos de talla con algún golpe de buril, etc. Todas estas piezas integrarían el grupo de diversos, con un porcentaje medio en torno al $13 \%$, y donde las lascas con retoques representan internamente cerca del $80 \%$, lo que testimonia la precaria entidad de los útiles de substrato.

Frente a este componente tipológico entrevisto, definido por el retoque (utillaje retocado), hay que señalar en el Neolítico Antiguo cardial la gran abundancia de piezas que solamente presentan lo que consideramos simples señales de utilización, categorizadas como utillaje no retocado. El utillaje no retocado estaría constituido por una serie de productos (lascas, láminas y laminitas) sin más características morfológicas que las que les confiere básicamente su talla, su generalizada y específica preparación secundaria (por fracturación intencional) y su probable y concreta utilización. Los caracteres 

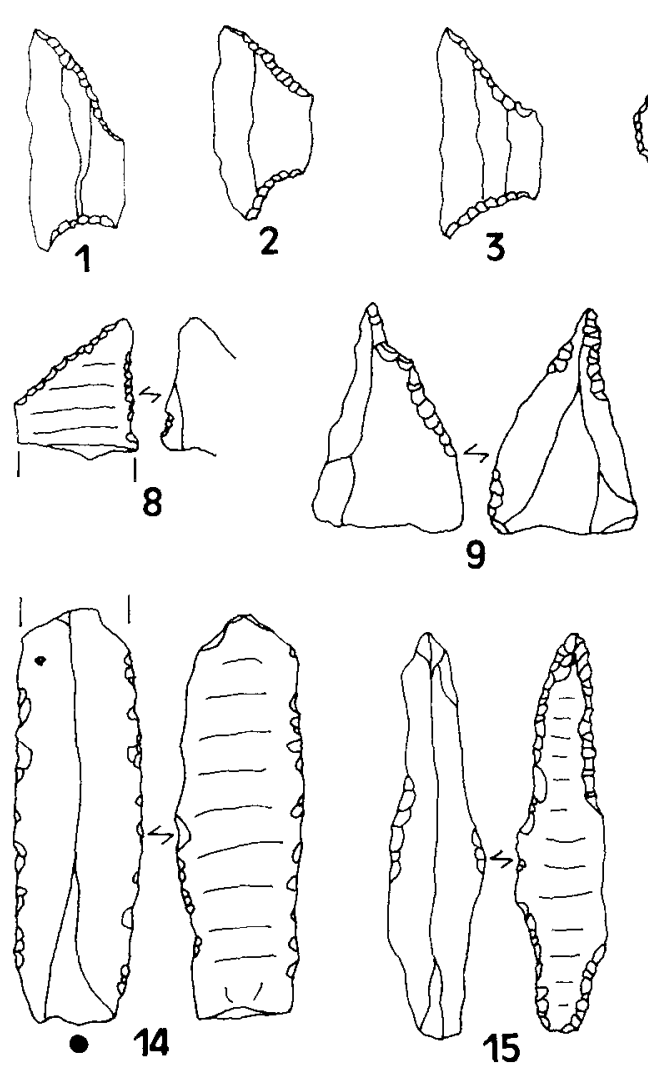

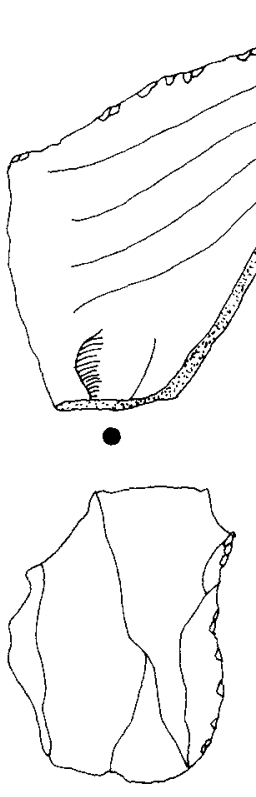

19
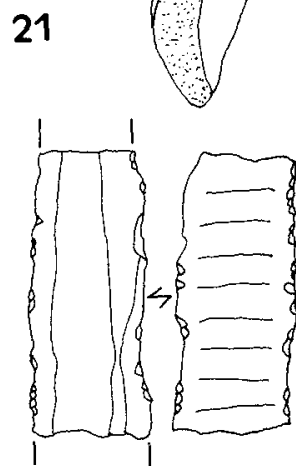

20
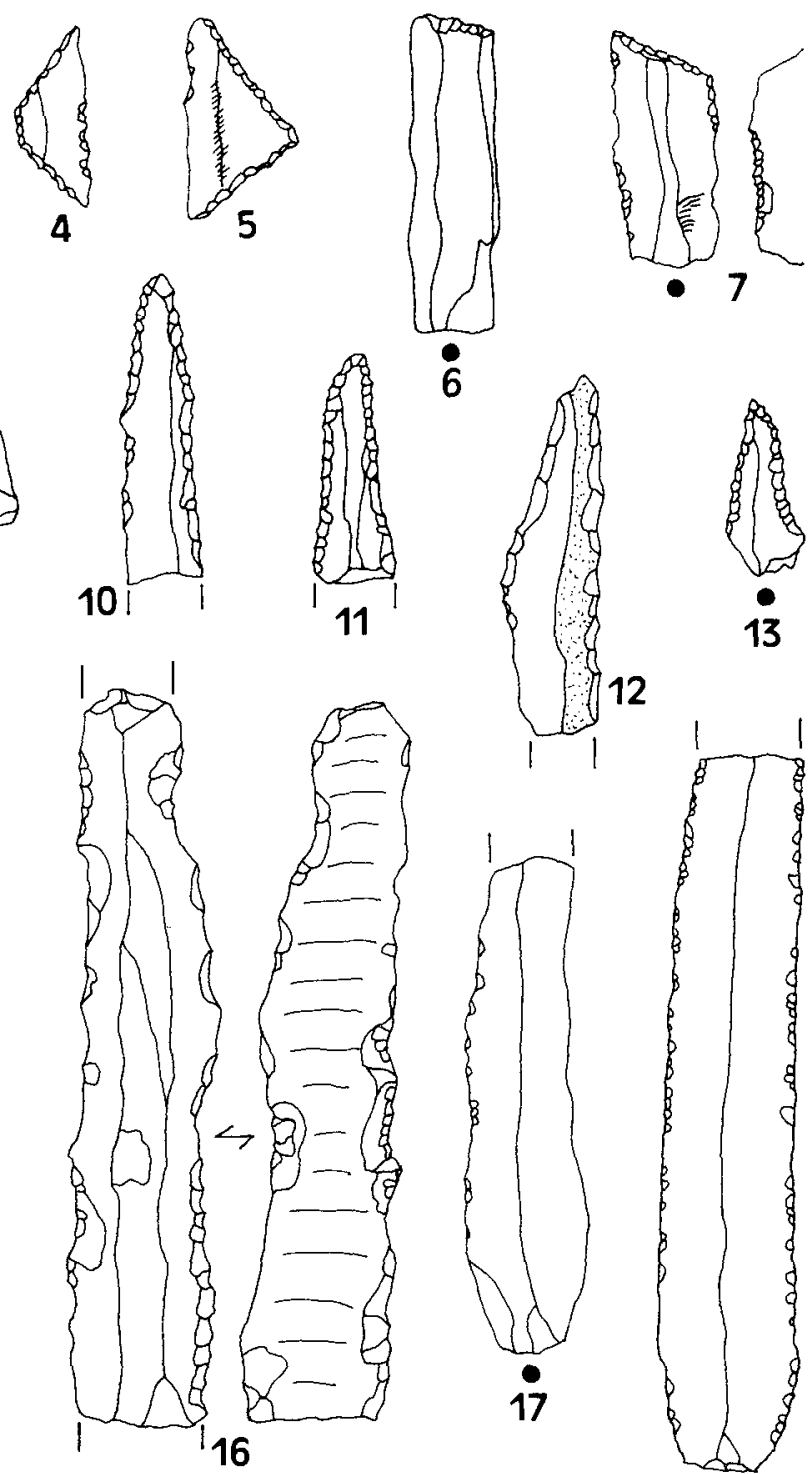

13

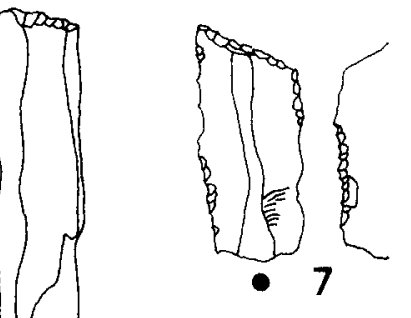

6
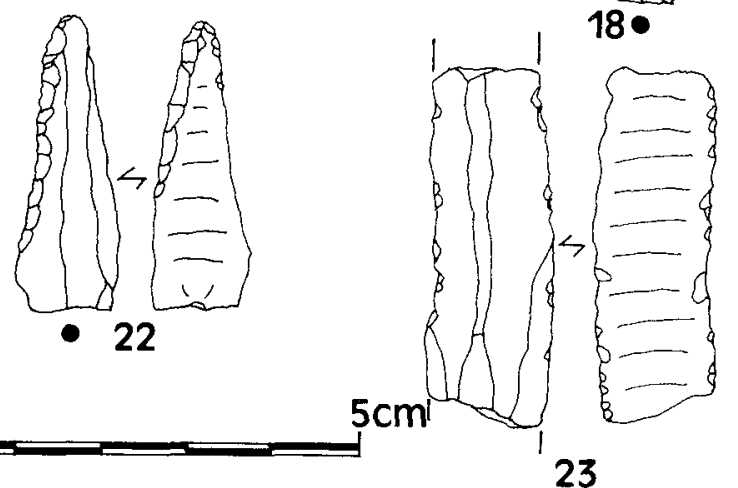

Fig. 3. - Utillaje en silex neolítico (Cova de l'Or y Cova de la Sarsa). N. ${ }^{\circ} 1$ a $4:$ trapecios. N. ${ }^{\circ}$ 5: triángulo. N. ${ }^{\circ} 6$ a 8 : truncaduras. N. ${ }^{\circ}$ 9: perforador. $\mathrm{N} .{ }^{\circ} 10$ a 13,15 y 22 : taladros. $\mathrm{N} .{ }^{\circ} 14,17,18,20$ y 23 : láminas con retoques de uso. $\mathrm{N} .{ }^{\circ} 16$ : lámina con denticulación. N. 19 y 21 : lascas con retoques de uso. 

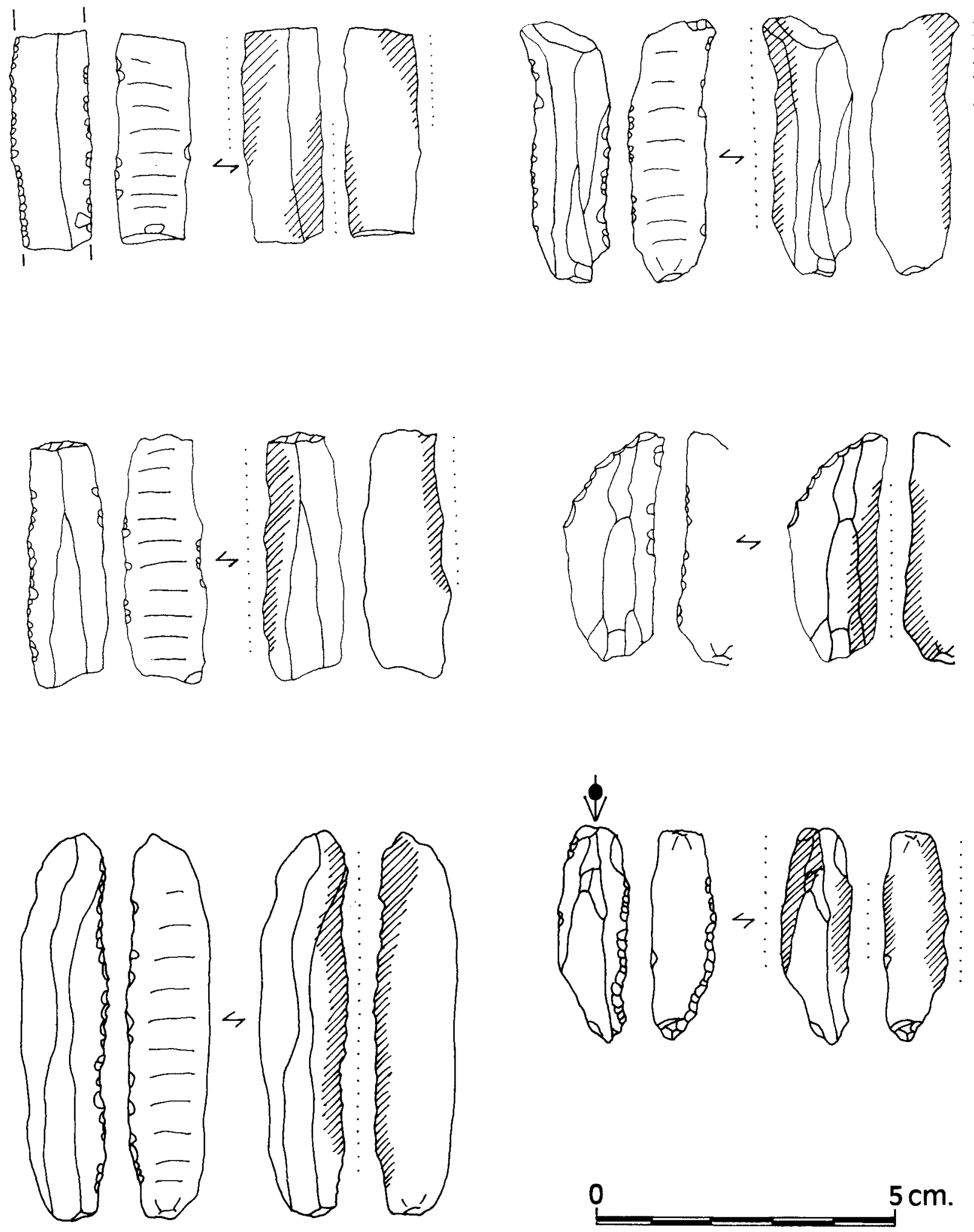

Fig. 4.-Morfología y extensión del lustre en algunos elementos de hoz de la Cova de l'Or. 
de utilización vendrían definidos por una serie de pequeñas muescas y descamaciones dispuestas arbitrariamente sobre el filo o los filos brutos de las piezas, rasgos que, por otra parte, son perceptibles a simple vista. En un sentido general se trataría de lo que Bordes (1970) ha definido como «útiles a posteriori», o lo que Guilaine (GUILAINE et alii, 1979) ha designado como pièces à fil ébréché. Los útiles por uso pueden representar el $45 \%$ del total del utillaje efectivo cardial (retocado y no retocado); internamente predominan las piezas sobre soportes laminares, que totalizan más del $80 \%$. Estos datos, pues, son ilustrativos de la gran significación que reviste el utillaje no retocado en contextos del Neolítico Antiguo cardial.

\subsection{FUNCIONALIDAD}

Tal como ha subrayado Cauvin $(1968,33$ y 1983), es evidente que los materiales neolíticos, por su naturaleza, son muy susceptibles de un estudio de índole funcional, viable para deducir todo tipo de consideraciones etno-económicas. Partiendo de la idea de que en el Neolítico las funciones vienen mejor determinadas por la forma de los útiles, las precisas trazas de uso, etc., y dejando de lado dadas nuestras limitaciones al respecto- problemas específicos de un estudio funcional tal como lo entendemos en su estricto terreno metodológico (cinemática del trabajo, caracterización de las microtrazas de uso y desgaste, etc), nos ceñiremos en este apartado a sugerir solamente el que podríamos llamar campo tecno-económico (o campo de actividad) de algunas de las series líticas entrevistas; siempre desde una perspectiva enteramente lógica y bajo el presupuesto de la anteriormente aducida correlación forma-función, así como de las concretas aportaciones bibliográficas sobre el particular.

La industria lítica del Neolítico antiguo cardial de la zona estudiada ofrece el problema de que la asociación útil actividad es más clara en unos casos que en otros, y asimismo, y a falta en el momento actual de estudios precisos -en términos evolutivos- para su utillaje, el hecho de que es bastante difícil llegar a discernir con claridad el desarrollo concomitante de algunas familias de útiles; procedimiento éste que, por otra parte, nos permitiría tal vez delimitar grupos tecno-económicos estables, ligados a una misma actividad o trabajo (CAUVIN, $1968,25)$, y con ello la funcionalidad de alguna de las familias concernidas, por su relación con otras integrantes cuyo campo de actividad es ya conocido.

De este modo, y redundando en las expuestas limitaciones que nos impiden hablar en algunos casos con mayor propiedad, un grupo con una funcionalidad bastante bien definida en la industria valorada sería el constituido por los perforadores y los taladros. Su catalogación como útiles dedicados básicamente al trabajo de la madera vendría sugerida por las referencias de Cauvin $(1968,162)$, en la medida que las piezas de estas características de l'Or o la Sarsa no difieren demasiado, en cuanto a morfología y traceología de uso, de las estudiadas por este autor. De otro lado, remarcaríamos que el empleo de estos útiles en el trabajo de la madera, y en contextos neolíticos, ha sido confirmada más recientemente por otros autores desde una perspectiva analítica estrictamente funcional (KEELEY, 1983; CAHEN y GYSELS, 1983; CAHEN y CASPAR, 1984). Con todo, no hay que olvidar los caracteres de reutilización, usos múltiples u ocasionales que pueden presentar la mayor parte de los útiles prehistóricos; de este modo, los perforadores y sobre todo los taladros han podido emplearse, esporádicamente y en nuestro caso, en la confección de orificios de lañado en vasos cerámicos, o en el trabajo de materias minerales (CAHEN y GYSELS, 1983), entre otras tareas más enventuales.

Para otros grupos de piezas, con muescas, denticulaciones, retoques irregulares, etc., su campo de actividad es más difícil de discernir. Tradicionalmente muescas y denticulados se han atribuido también al trabajo de la madera o el hueso, en la preparación de astiles y montantes, por lo que en cierta forma podrían constituir un mismo grupo tecnoeconómico junto con los taladros.

Las lascas con retoques, que parecen sustituir a los raspadores en su mismo sentido funcional ( $\mathrm{RO}$ ZOY, 1978, 939), o las del tipo raedera, pueden ofrecer un campo de utilización bastante amplio, común a todos los útiles de sustrato o útiles estereotipados que, por lo general, vienen marcados por una menor especialiación de uso que los útiles específicamente neolíticos (CAUVIN, 1983); su empleo iría desde el propio trabajo de la madera al adobe de las pieles.

Algunas de las piezas laminares con retoques más regulares y marginales, continuos o no, o con simples señales de utilización, se acercarían claramente a la estricta idea funcional del «cuchillo», sobre todo las láminas y laminitas utilizadas en bruto 
(ROY, 1983; CAHEN y CASPAR, 1984, 295), y podrían circunscribirse en la órbita de las actividades más puramente domésticas (por ejemplo, el despiece de la caza).

A los geométricos habría que atribuirles un papel de mero armamento, en relación con la caza, complemento de las actividades productivas que revelan los yacimientos cardiales. En este sentido, trapecios, segmentos y triángulos constituirían las verdaderas armaduras del Neolítico Antiguo, destinadas a guarnecer todo tipo de flechas y azagayas, continuando así la tradición y funcionalidad que ya desde el Epipaleolítico se había atribuido a estas piezas (CLARKE, 1976; ODELL, 1978; ROZOY, 1978).

Capítulo a parte merecen los elementos de hoz, piezas que, desde una perspectiva funcional y dentro del apartado de las que presentan lustre, constituyen la categoría de utensilios con mayor significación del equipamiento lítico cardial del área estudiada. Este tipo de armaduras vendrían definidas funcionalmente por su perceptible pátina brillante, y su campo de actividad —salvando otras utilizaciones que puede sugerir el lustre (PERLĖS y VAUGHAN, 1983; CAHEN y CASPAR, 1984, 305) - se circunscribiría al del utillaje agrícola (ANDERSON-GERFAUD, 1982), como piezas integrantes de hoces compuestas (MONTEAGUDO, 1956; COURTIN y ERROUX, 1974; HELMER, 1983).

En el caso de l'Or y la Sarsa, los elementos de hoz se caracterizan por cubrir un amplio espectro morfológico, sobre todo en el primer yacimiento, encontrándose representados en casi todas las familias tipológicas anteriormente reseñadas (utillaje retocado), si bien su mayor número lo proporcionan las láminas y laminitas con simples señales de utilización (utillaje no retocado). En cuanto al utillaje retocado, la preponderancia de piezas con lustre corresponde a láminas y laminitas retocadas, principalmente con retoques marginales, con escotadura o preparación terminal y con retoques irregulares; seguirían las truncaduras y las láminas y laminitas con muesca o denticulación, siendo escasos los geométricos con lustre y que hayan tenido esta funcionalidad.

Por otro lado, los elementos de hoz son en sí mismos un claro exponente de la orientación tecnológica general de la industria lítica cardial, en la medida en que la mayor parte de los caracteres morfotécnicos observados en el utillaje están en relación con esa precisa tecno-funcionalidad: desde los que irían encaminados a conseguir unos productos estereotipados, como las fracturas intencionales o las truncaduras, a los que buscarían una simple solución de acomodamiento, sobre todo en el sentido de favorecer el ensamblaje de las piezas en serie y su sujeción al fondo de la ranura de un montante; de acuerdo con esta última intención estarían las propias fracturas (retocadas o no), las escotaduras y preparaciones terminales, algunos retoques laterales parciales, etc.

Sobre su exacta significación, habría que señalar que los elementos de hoz representan alrededor del $12 \%$ del utillaje efectivo en yacimientos como l'Or y la Sarsa, debiéndose asimismo recalcar que han sido determinados estrictamente en ambos yacimientos, a la hora de su recuento efectivo, a partir de la presencia constatable del «lustre de cereales». Desde esta perspectiva, el porcentaje apuntado de armaduras de hoz puede no reflejar todas las piezas que hayan trabajado en tal sentido, en la medida en que el lustre no es el único carácter determinante de esa función, dada la multivariedad de factores que pueden intervenir en su formación y también en su deterioro (MASSON, COQUELIGNOT y ROY, 1981; MASSON, 1982; BEYRIES, 1982; GYSELS y CAHEN, 1982); por tanto, y aunque la proposición pueda formularse inversamente, parece más lógico que gran número de útiles que no presentan pátina brillante han podido haber actuado muy bien como elementos de hoz.

Así, pues, el estudio de los elementos de hoz permite inferir toda una serie de precisiones sobre la tecnología y la funcionalidad de la industria lítica cardial, sugiriéndonos las siguientes propuestas:

- que se trata de una industria orientada hacia el útil compuesto.

- y que se trata, en esencia, de una industria para hoces.

Tras las valoraciones expuestas en los anteriores apartados, y ofreciendo una visión sintética, las características fundamentales de la industria lítica tallada del Neolítico Antiguo de la vertiente mediterránea de la Península Ibérica quedarían así definidas:

- Al nivel de la tecnología básica:

- El sílex como materia prima casi exclusiva.

- Láminas y laminitas como productos básicos (una talla especialmente dirigida a la producción de soportes laminares). 


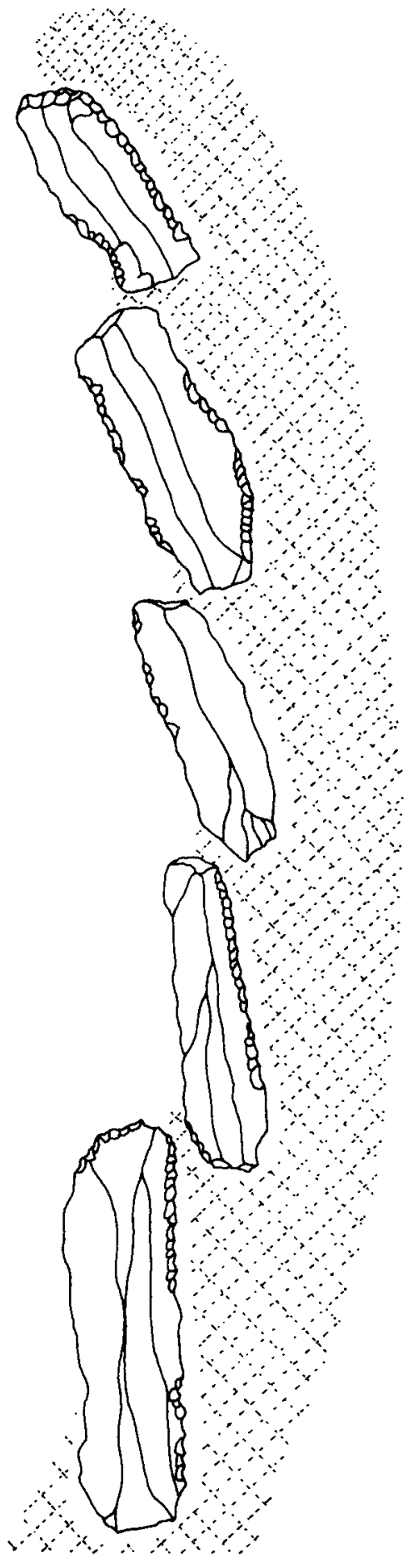

$5 \mathrm{~cm}$.

Fig. 5.- Reconstrucción de una hoz con elementos de la Cova de la Sarsa.
- Al nivel de la tecnología específica:

- Técnica de fractura por flexión o percusión (producción estereotipada por acortamiento sistemático de los soportes laminares; búsqueda del útil compuesto).

- Ausencia de la técnica del microburil.

- Predominio del retoque marginal simple, o simple de tendencia abrupta (conjunto laminar retocado); seguido del retoque abrupto (geométricos, truncaduras y taladros).

- Precariedad del retoque en doble bisel.

- Ausencia de la técnica de buril.

- Al nivel de la tipología morfológica y del utillaje en general:

- Precariedad o ausencia de los útiles de sustrato (raspadores, buriles y laminitas de borde abatido).

- Geometrismo dominado por un fuerte componente trapezoidal.

- Aparición de los taladros.

- Gran significación del utillaje no retocado (especialmente láminas y laminitas utilizadas en bruto).

- Al nivel de la funcionalidad:

- Gran significación del utillaje agrícola (elementos de hoz).

\section{COMPARACIONES LÍTICAS ENTRE EL NEOLÍTICO ANTIGUO Y EL COMPLEJO EPIPALEOLÍTICO GEOMÉTRICO DE FACIES COCINA}

Según vimos en el punto 1, el Complejo Epipaleolítico de facies Cocina, definido por Fortea (1973), constituye el sustrato sobre el que se realizó la completa neolitización en el área que nos ocupa. Concretamente, sus fases $\mathrm{C}$ y D, caracterizadas a partir de los momentos evolutivos III y IV de la Cueva de la Cocina (FORTEA, 1971 y 1973), y matizadas en sus constantes tecno-industriales por las aportaciones recientes de yacimientos como Botiquería dels Moros (Mazaleón, Teruel), niveles 6, 7 y 8 (BARANDIARÁN, 1978), y Costalena (Maella, Teruel), niveles c-2, c-1 y b y a (BARANDIARÁN y CAVA, 1981), son las que claramente asisten al proceso de la neotilización, ofreciento las bases para una comparación lítica con el Neolítico Antiguo cardial.

En el terreno industrial, y a grandes rasgos, la Fase $C$ (primera que ofrece evidencias cerámicas) 

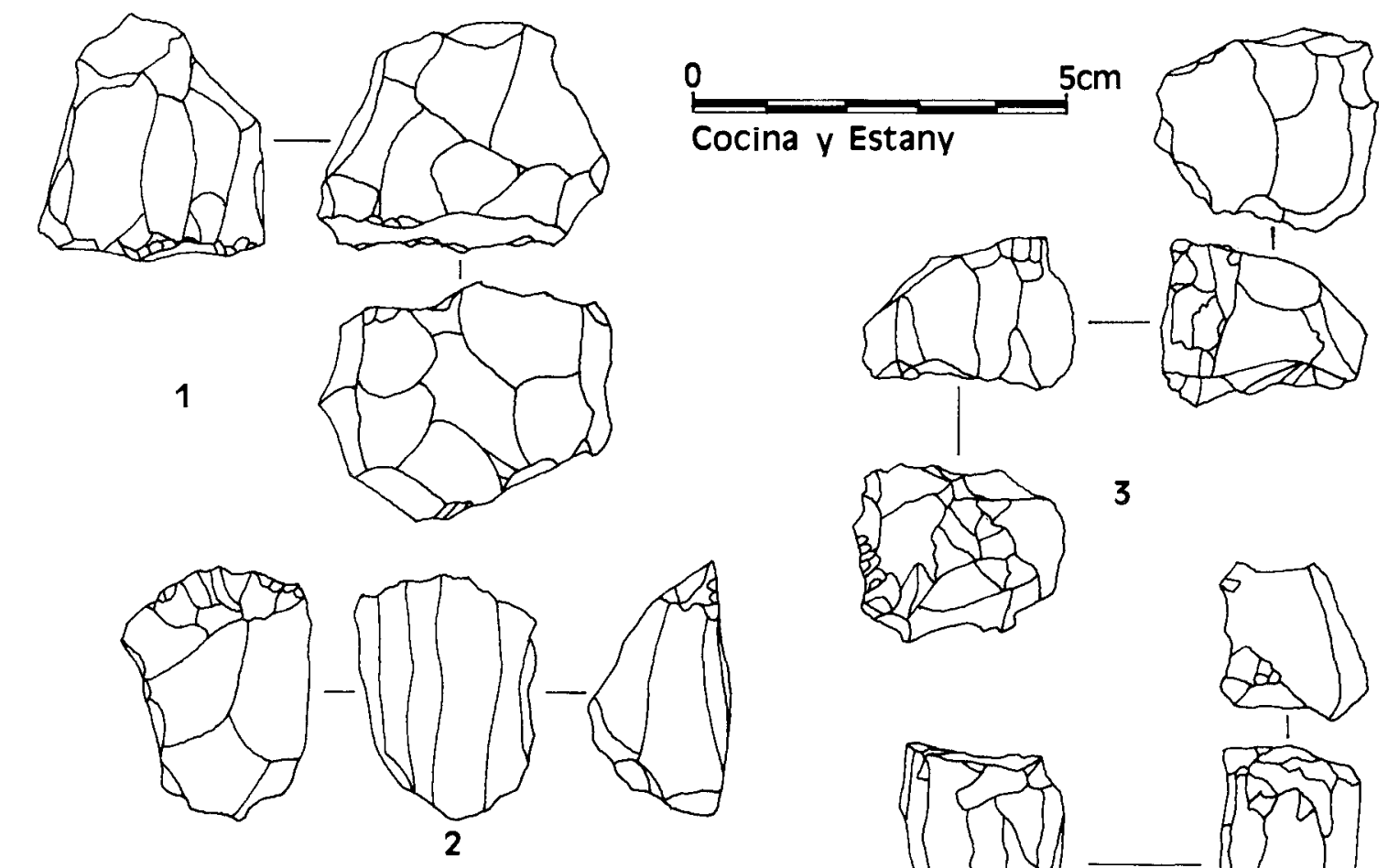

3
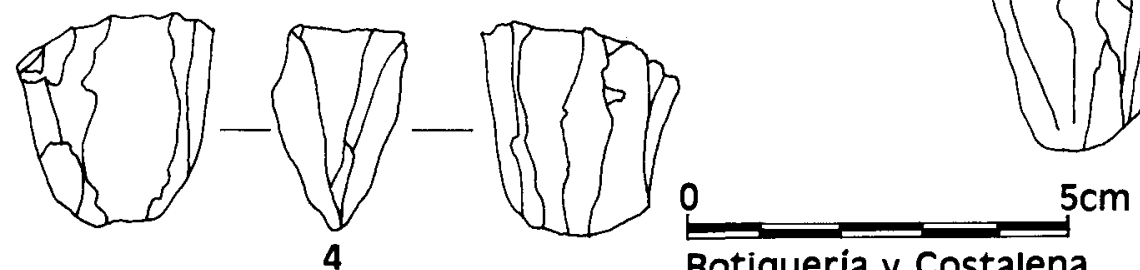

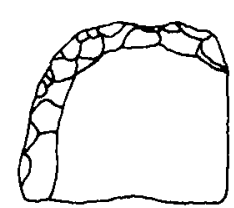

6

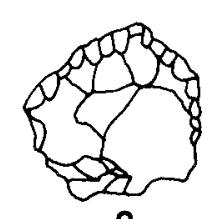

9

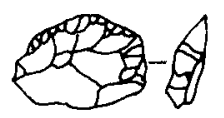

12
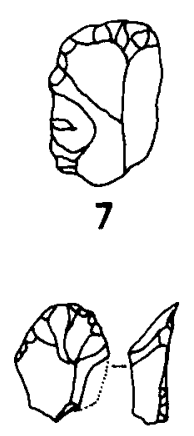

10

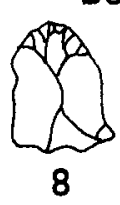

8

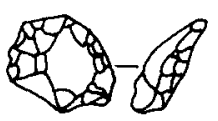

11

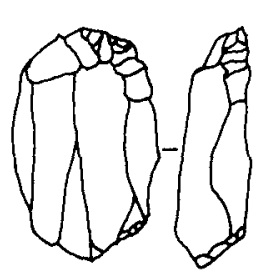

14

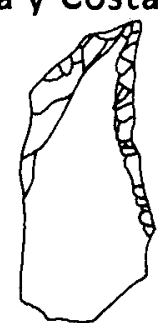

15

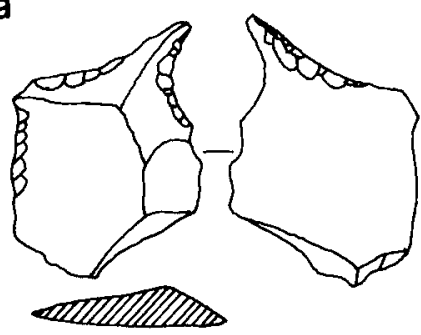

16

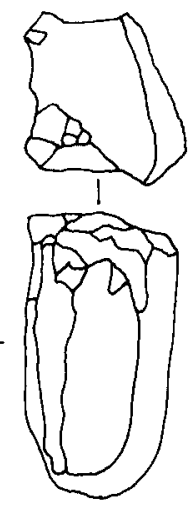

Fig. 6.-Utillaje en sílex epipaleolítico sincrónico al Neolítico (Botiqueria dels Moros, Costalena, Estany Gran y Cocina). N. ${ }^{\circ} 1$ a 5: núcleos. N. ${ }^{\circ} 6$ a 14: raspadores. N. ${ }^{\circ} 15$ y 16: perforadores. N. ${ }^{\circ} 17$ y 18: buriles. (Botiqueria: n. ${ }^{\circ} 1,2,10,11$ y 16. Costalena: ก. ${ }^{\circ} 12,13,14,17$ y 18 . Estany: $n .^{\circ} 3$ a 8 . Cocina: n. ${ }^{\circ} 9$ ). 


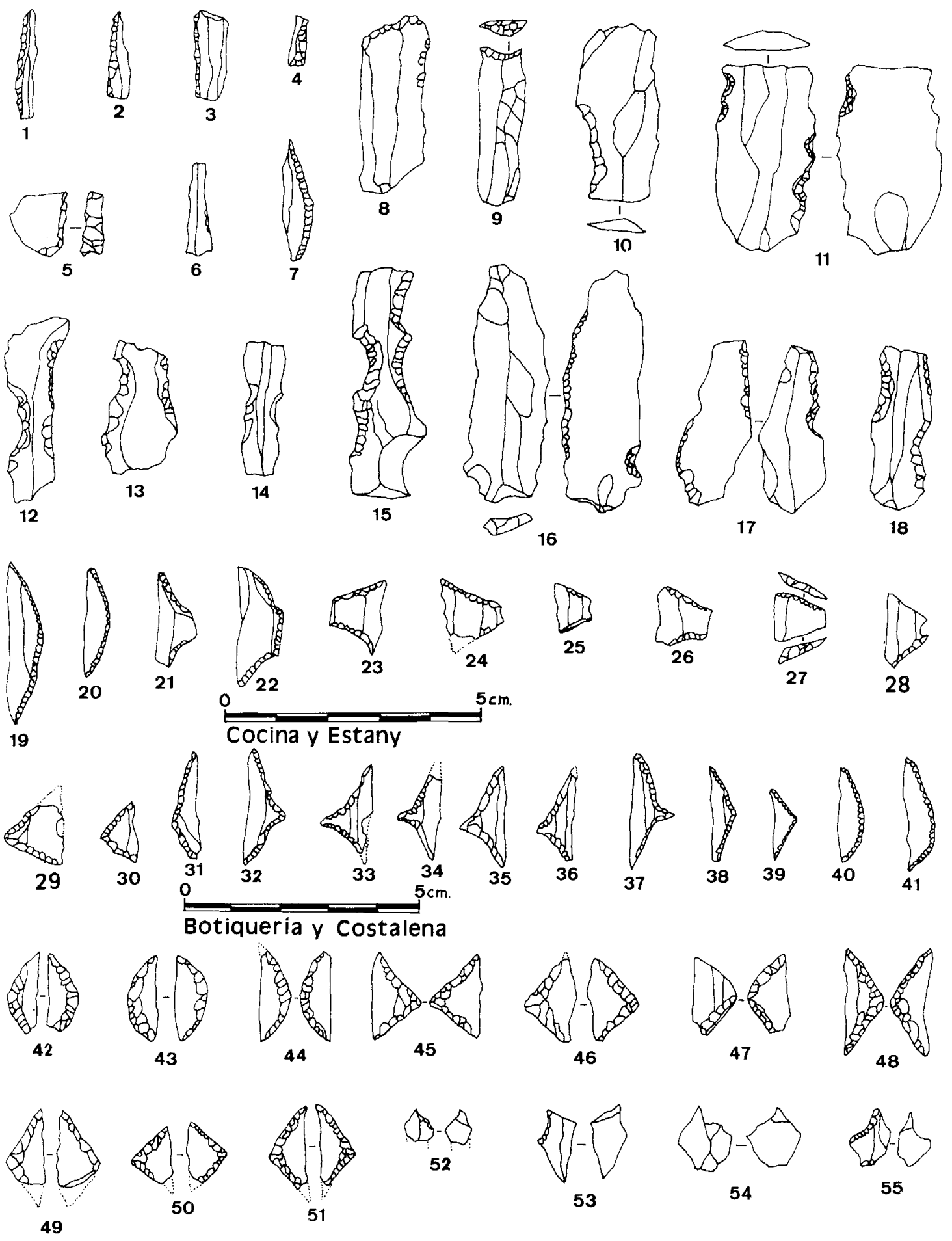

Fig. 7.-Utillaje en sílex epipaleolítico sincrónico al Neolítico (Botiqueria dels Moros, Costalena, Estany Gran y Cocina). N. ${ }^{\circ}$ a 7: laminitas de borde abatido. N. ${ }^{\circ} 8$ y 9: truncaduras. N. ${ }^{\circ} 10$ a 18 : láminas y laminitas con muesca o denticulación. N. ${ }^{\circ} 19$ a 41 : geométricos de borde abatido. N. ${ }^{\circ} 42$ a 51 : geométricos de borde en doble bisel. N. ${ }^{\circ} 52$ a 55 : microburiles. (Botiqueria: $n .{ }^{\circ} 6,10$, $11,16,17,23$ a $26,29,30$ y 42 a 52 . Costalena: n. ${ }^{\circ} 9,18,27,28,33$ a 36 y 42 a 48 . Estany: n. ${ }^{\circ} 1$ a $5,8,12,13,31,32$ y 35. Cocina: n. $7,14,15,19$ a 22,37 a 41,53 y 54$)$. 
manifestaría la incorporación de todos los elementos constatados en las fases anteriores (A y B, antecerámicas), notándose un resurgimiento de las formas de vieja tradición (raspadores, hojitas de dorso, etc.) y un fuerte desarrollo geométrico con predominio de segmentos o triángulos según los yacimientos, con escasos trapecios; destacaríamos que estas piezas se encuentran elaboradas a partir de las técnicas del microburil y del doble bisel, actuando ambas conjuntamente, y respectivamente sobre determinadas categorías y subclases morfológicas: la primera (ligada al retoque abrupto), sobre trapecios y triángulos en general; la segunda, mayoritariamente sobre segmentos y triángulos isósceles. Todos estos componentes, junto con las hojitas apuntadas con la espina central tipo Cocina (específicas a este yacimiento) y la relativa proporción de muescas y denticulados, constituirían los elementos definidores de la fase en lo lítico.

La Fase $D$, que recubre los últimos momentos epipaleolíticos y que se encuentra deficientemente representada - en cuanto a efectivos industrialesen yacimientos en cueva o abrigo, vendría marcada fundamentalmente por el empleo masivo del doble bisel (simple o invasor) en los geométricos, abundando los segmentos con esta técnica, así como los triángulos isósceles; en ciertos yacimientos se produciría una reactivación de los trapecios (Cocina), aunque la tónica general parece ser la mayor continuidad de los triángulos. Por otro lado, no se descartaría la posibilidad - dentro de esta fase- de ciertos desarrollos regionales que, en algunos casos, podrían propiciar la pervivencia de la tradición epipaleolítica (en técnicas y formas) en etapas cronológicamente bastante avanzadas.

Los contrastes de esta industria con la cardial son del todo evidentes (FORTEA, 1973; MARTÍ y JUAN-CABANILLES, 1984). En todos los niveles (tecnológico, morfológico y de la funcionalidad) se atisba el distanciamiento industrial, que podemos abordarlo rápidamente por el capítulo de las respectivas presencias y ausencias más notables. En el estricto campo de la morfología y la funcionalidad, faltan en las fases cronológicamente neolíticas de la tradición epipaleolítica los taladros y los elementos de hoz, y por consiguiente todo el repertorio laminar morfo-técnicamente adecuado para esta segunda función. Faltan en el Neolítico Antiguo cardial útiles típicos de substrato, tales como los buriles, escasos pero presentes en los yacimientos epipaleolíticos de facies Cocina; las laminitas con borde aba- tido, entre ellas las características hojitas con espina central (Cocina); las peculiares láminas estranguladas por muescas bilaterales; en algún modo los raspadores, etc. Unicamente el común apartado de los geométricos podría sugerir algún tipo de relación; pero aun aquí se observan marcadas y significativas distancias (JUAN-CABANILLES, 1985). Así, y en cuanto a la morfología, en contextos cardiales son predominantes los trapecios, y apenas se constatan los triángulos, por otra parte bastante atípicos; contrariamente, los trapecios son generalmente escasos en las primeras fases sincrónicas epipaleolíticas, mientras que los triángulos suelen ser las formas dominantes (Botiquería y Costalena), ofreciendo gran diversificación. Respecto a la tecnología, en el Neolítico Antiguo cardial no aparece la técnica del microburil, a pesar de ser el retoque abrupto casi exclusivo en todas sus variantes formales geométricas, estando la técnica del doble bisel escasamente representada.

En líneas generales, éstas serían las diferencias más destacadas, por lo que podría afirmarse que las industrias líticas contemporáneas del Epipaleolítico de facies Cocina y del Neolítico Antiguo cardial del área que nos ocupa responden a tradiciones distintas. Esto vendría apoyado por el hecho de que el Epipaleolítico de facies Cocina muestra una particular evolución industrial que parece no detenerse con la llegada de los primeros influjos neolíticos; es decir, que en los primeros niveles cerámicos de yacimientos como Cocina, Botiquería o Costalena no se ve alterada en lo lítico la subyacente estructura epipaleolítica, por lo demás sí matizada en su propia dinámica interna.

\section{LA ARTICULACION CULTURAL}

La consideración de esta dualidad industrial entrevista y dentro de un marco de caracterización, permite encuadrar en la distintas tradiciones, epipaleolítica o neolítica pura, a gran parte de los primeros yacimientos cerámicos de la vertiente mediterránea ibérica, así como de otras áreas limítrofes también peninsulares.

Bien acordes con el modelo representado por Cocina, Botiquería o Costalena estarían gran número de estaciones detectadas en el ámbito mediterráneo. En el País Valenciano, donde mayor concentración de ellas existe, destacan los hallazgos del Estany Gran (Almenara, Castelló) (FORTEA, 1975) y de 
los Covachos de Can Ballester (la Vall d'Uixó, Castelló) (GUSI y OLARIA, 1979), situados en la plana litoral; en una distribución más serrana e interior se encontrarían la Covacha de Llatas (Andilla, València) (JORDÁ y ALCÁCER, 1949; FORTEA, 1973) y un grupo de yacimientos emplazados en una serie de cuencas endorreicas, generalmente asentamientos al aire libre, tales como los de la Albufera (Anna, València) y los de la Casa de Lara y el Arenal de la Virgen (ambos en Villena, Alacant) (SOLER, 1961 y 1965; FORTEA, 1973), entre otros.

Más hacia el Sur, la tradición epipaleolítica de facies cocina ha podido constatarse en comarcas de la Andalucía oriental, una marco que hasta ahora había pasado incógnito por lo que a este tipo de evidencias se refiere. Claros indicios han sido determinados en los niveles antecerámicos de la estación de Valdecuevas (Cazorla, Jaén) (SARRIÓN, 1980), pudiendo muy bien corresponder a la misma tradición, y a falta de un estudio más profundo, las escasas piezas líticas que acompañan aquí a las primeras cerámicas; más preciso es el caso de la Cueva del Nacimiento (Pontones, Jaén) (RODRÍGUEZ, 1979; ASQUERINO y LÓPEZ, 1981), ya que este yacimiento ofrece un fuerte componente geométrico, de clara raíz epipaleolítica, en un contexto cerámico del Neolítico medio andaluz. Una vez más, estos datos incidirían en el carácter complejo que revisten las últimas fases epipaleolíticas consecuentemente a la neolitización, lo que viene a delimitar un cuadro de precisas interacciones, extremándose con ello las bases interpretativas actuales.

Por su parte, la tradición lítica cardial encontraría su correlato en los yacimientos propios de la llamada Cultura de las Cerámicas Impresas, así como en aquellos otros que pudiendo corresponder a fases más avanzadas de la Cultura o a facies parcialmente distintas (BERNABEU, 1982), se sitúan en la órbita industrial de los grupos neolíticos puros. Dependiendo de la mayor o menor riqueza de los conjuntos conocidos, este sería el caso de la Cova de les Cendres (Teulada, Alacant) (LLOBREGAT et alii, 1981), en el ámbito valenciano; o de la Cueva de la Carigüela (Piñar, Granada) (PELLICER, 1964; NAVARRETE, 1976), yacimiento éste que ha sido objeto recientemente de una revisión de sus materiales líticos, dentro de un programa de estudio más general de las industrias líticas del Neolítico al Bronce en el marco de la Andalucía oriental (MARTÍNEZ, 1985); así como de otras estaciones también situadas en el área andaluza, entre las que citaríamos la Cueva de Nerja (Nerja, Málaga) (PELLICER, 1963) y la Cueva de los Murciélagos (Zuheros, Córdoba) (VICENT y MUÑOZ, 1973); a los que habria que añadir diversos yacimientos catalanes, en especial les Guixeres (Vilobí, Barcelona) (BALDELLOU y MESTRES, 1981), uno de los pocos asentamientos al aire libre del Neolítico Antiguo conocidos actualmente en la fachada mediterránea ibérica.

\section{POST SCRIPTUM}

Ya redactada y enviada la presente comunicación, tuvimos conocimiento de la publicación de la Cueva de Chaves de Bastarás (Casbas, Huesca) (V. BALDELLOU et alii: BOLSKAN, 1, Huesca, 1983, pp. 9-137), yacimiento del que se tenían escuetas noticias y que ha revelado una importante ocupación del Neolítico antiguo cardial. La Cueva de Chaves constituye, pues, un jalón septentrional más de la pura tradición neolítica representada por Or o Sarsa, viniendo a confirmar su industria lítica, estudiada por A. Cava, esta filiación cultural.

\section{BIBLIOGRAFÍA}

ANDERSON-GERFAUD, P., 1982: «Comment préciser l'utilisation agricole des outils préhistoriques?» Cahiers de l'Euphrate, 3 , pp. 149-164.

ASQUERINO, M. D., 1978: «Cova de la Sarsa (Bocairente, Valencia). Análisis estadístico y tipológico de materiales sin estratigrafía (1971-1974)». Papeles del Laboratorio de Arqueologia de Valencia-Saguntum, 13, pp. 99-225.

ASQUERINO, M. D. y LOPEZ, P., 1981: «La Cueva del Nacimiento (Pontones): un yacimiento neolítico en la sierra del Segura.»Trabajos de Prehistoria, vol. 38, pp. 109-133.

BALDELLOU, V. y MESTRES, J., 1981: «Les Guixeres de Vilobí, hàbitat del Neolític Antic a l'aire lliure.» En El neolt' lic a Catalunya (Taula rodona de Montserrat, maig del 1980). Publicacions de l'Abadia de Montserrat, pp. 69-74.

BARANDIARAN, I., 1978: «El Abrigo de la Botiqueria dels Moros. Mazaleón (Teruel). Excavaciones arqueológicas de 1974. Cuadernos de Prehistoria y Arqueologia Castellonense, 5, pp. 49-138.

BARANDIARAN, I. y CAVA, A., 1981: «Epipaleolítico y neolítico en el Abrigo de Costalena (Bajo Aragón).» Bajo Aragón, Prehistoria, 3, pp. 5-20.

BERNABEU, J., 1982: «La evolución del Neolítico en el País Valenciano. Aportaciones al estudio de las culturas neolíticas en el extremo occidental del Mediterráneo.» Revista de Investigación y Ensayos del Instituto de Estudios Alicantinos, 37, sept.-dic., pp. 85-137. 
BEYRIES, S., 1982: «Comparaison des traces d'utilisation sur différentes roches siliceuses.) Studia Praehistorica Belgica, 2, pp. 235-240.

BORDES, F., 1970: «Réflexions sur l'outil au Paléolithique.»Bulletin de la Société Préhistorique Française, t. 67, pp. 199-202.

CAHEN, D. y GYSELS, J., 1983: «Techniques et fonctions dans l'industrie lithique du groupe de Blicquy (Belgique).»Travaux de la Maison de l'Orient, 5, pp. 37-52.

CAHEN, D. y CASPAR, J.-P., 1984: «Les traces d'utilisation des outils préhistoriques.» I'Antropologie, t. 88, n. ${ }^{\circ} 3$, pp. 277-308.

CAUVIN, J. 1968: «Les outillages néolithiques de Byblos et du littoral libanais». En Fouilles de Byblos de DUNAND, M., T. IV, Paris, Librairie d'Amérique et d'Orient, $360 \mathrm{p}$.

CAUVIN, J., 1983: «Typologie et fonctions des outils préhistoriques: apports de la tracéologie a un vieux débat.»Travaux de la Maison de l'Orient, 5, pp. 259-274.

CLARKE, D., 1976: «Mesolithic Europe: the economic basis.» En Problems in Economic and Social Anthropology de SIEVEKING, G. de G. et alii (editores), Duckworth-London, pp. 449-481.

COURTIN, J. y ERROUX, J., 1974: «Aperçu sur l'agriculture préhistorique dans le Sud-Est de la France.» Bulletin de la Société Préhistorique Francaise, t. 71, fasc. 1, pp. 321-334.

FLETCHER, D., 1962: «Toneles cerámicos neolíticos.»VII Congreso Nacional de Arqueologia (Barcelona, 1961), Zaragoza, pp. 148-151.

FORTEA, J. 1971: La Cueva de la Cocina. Ensayo de cronología del Epipaleolítico (facies geométrica). Trabajos varios del Servicio de Investigación Prehistórica, n. ${ }^{\circ} 40$, Valencia, $88 \mathrm{p}$.

FORTEA, J., 1973: Los Complejos Microlaminares y Geométricos del Epipaleolitico mediterráneo español. Memorias del Seminario de Prehistoria y Arqueología, n. ${ }^{\circ} 4$, Salamanca $545 \mathrm{p}$.

FORTEA, J., 1975: «Tipología, habitat y cronología relativa del Estany Gran de Almenara.» Cuadernos de Prehistoria y Arqueología Castellonense, 2, pp. 22-38.

FORTEA, J. y MARTI, B., 1984-85: «Consideraciones sobre los inicios del Neolítico en el Mediterráneo español.» Zephyrus, XXXVII-XXXVIII, pp. 164-199.

FORTEA, J.; MARTI, B.; FUMANAL, P.; DUPRÉ, M. y PEREZ, M., 1987: «Epipaleolítico y neolitización en la zona oriental de la Península Ibérica.» En Premières Communautés Paysannes en Méditerranée Occidentale, Montpellier, pp. 581-592.

G. E. E. M., 1969: «Les microlithes géométriques.»Bulletin de la Société Préhistorique Française, t. 66, pp. 355-366.

GUILAINE, J.; GASCO, J.; VAQUER, J.; BARBAZA, M. et alii, 1979: L'Abri Jean Cros. Essai d'approche d'un groupe humain du Néolithique ancien dans son environnement. Centre d'Antropologie des Sociétés Rurales, Toulouse, $461 \mathrm{p}$.

GUSI, F. y OLARIA, C., 1979: «El yacimiento prehistórico de Can Ballester (Vall d'Uixó, Castellón).» Cuadernos de Prehistoria y Arqueologia Castellonense, 6, pp. 39-95.

GYSELS, J. y CAHEN, D., 1982: «le lustre des faucilles et les autres traces d'usage des outils en silex.» Bulletin de la Société Préhistorique Française, t. 79, n. ${ }^{\circ} 7$, pp. 221-224.

HELMER, D., 1983: «Les faucilles et les gestes de la moisson.»Travaux de la Maixon de l'Orient, 5, pp. 189-198.

JORDA, F. y ALCACER, J., 1949: la Covacha de Llatas (Andilla). Trabajos Varios del Servicio de Investigación Prehistórica, n. ${ }^{\circ} 11$, Valencia, 41 p.

JUAN CABANILLES, J., 1983: Fonaments d'una tipologia litica per al Neolitic. Facultat de Geografia i Història de la
Universitat Literària de València. Tesi de llicenciatura (inèdita). Valencia, $235 \mathrm{p}$.

JUAN CABANILLES, J., 1984: «El utillaje neolítico en sílex del litoral mediterráneo peninsular.» Papeles del Laboratorio de Arqueología de Valencia, Saguntum, 18, pp. 49-102.

JUAN CABANILLES, J., 1985: «El Complejo Epipaleolítico Geométrico (facies Cocina) y sus relaciones con el Neolítico Antiguo.»Papeles del Laboratorio de Arqueología de Valencia, Saguntum, 19, pp. 9-30.

KEELEY, L.-H., 1983: «Neolithic novelties: the view from etnography and microwear analysis.» Travaux de la maison de l'Orient, 5, pp. 251-256.

LLOBREGAT, E.-A.; MARTI, B.; BERNABEU, J.; VILLAVERDE, V.; GALLART, M.-D.; PÉREZ, M.; ACUÑA, J.-D. y ROBLES, F. 1981: «Cova de les Cendres (Teulada, Alicante). Informe preliminar». Revista de Investigación y Ensayos del Instituto de Estudios Alicantinos, 34, pp. 87-111.

MARTI, B., 1977: Cova de l'Or (Beniarrés, Alicante). Vol. I. Trabajos Varios del Servicio de Investigación Prehistórica, n. ${ }^{\circ} 51$, Valencia, $92 \mathrm{p}$.

MARTI, B., 1983: «Cova de l'Or (Beniarrés, Alicante). Memoria de las Campañas de Excavación 1975-1979». Noticiario Arqueológico Hispánico, 16, pp. 11-38.

MARTI, B. y JUAN-CABANILLES, J., 1984: «Industrie lithique et Néolithique ancien dans le versant méditerranéen de la Peninsule Ibérique». Bulletin de la Société Méridionale de Spéléologie et de Préhistoire, t. XXIV, pp. 49-63.

MARTI, B.; PASCUAL, V.; GALLART, M.-D.; LOPEZ, P.; PEREZ, M.; ACUÑA, J.-D. y ROBLES, F., 1980: Cova de l'Or (Beniarrés, Alicante). Vol. 1I. Trabajos Varios del Servicio de Investigación Prehistórica, n. ${ }^{\circ}$ 65. Valencia, 280 p.

MARTI, B.; FORTEA, J.; BERNABEU, J.; PÉREZ, M.; ACUNA, J.-D.; ROBLES, F. y GALLART, M.-D., 1987: «El Neolítico Antiguo en la zona oriental de la Península Ibérica». En Premières Communautés Paysannes en Méditerranée Occidentale, Montpellier, pp. 607-620.

MARTINEZ, G., 1985: Análisis tecnológico y tipológico de las industrias liticas de la Prehistoria reciente en la Andalucía Oriental. Universidad de Granada. Tesis de doctorado (inédita). Granada.

MASSON, A., 1982: «Silice et traces d'usage: la part du silex». Nouvelles Archives du Museum d'Histoire Naturelle de Lyon (supplément au fascicule n. ${ }^{\circ} 20$ ), pp. 31-49.

MASSON, A.; COQUELIGNIOT, E. y ROY, S., 1981: «Silice et traces d'usage: le lustré des faucilles». Nouvelles Archives du Museum d'Histoire Naturelle de Lyon (supplément au fascicule n. ${ }^{\circ}$ 19), pp. 43-52.

MONTEAGUDO, L., 1956: «Hoces de sílex prehistóricas». Revista de Archivos, Bibliotecas y Museos, t. LXII, fasc. 2, pp. 457-534.

NAVARRETE, M.-S., 1976: La cultura de las Cuevas con cerámica decorada en Andalucia Oriental. Universidad de Granada, 2 vols., 431 y 415 p.

ODELL, G.-H., 1978: «Préliminaires d'une analyse fonctionnelle des pointes microlithiques de Bergumermeer (Pays Bas)». Bulletin de la Société Préhistorique Française, t. $75, \mathrm{n} .{ }^{\circ} 2$, pp. $37-49$.

PELLICER, M., 1963: Estratigrafía prehistórica de la Cueva de Nerja. 1. ${ }^{a}$ campaña. 1959. Excavaciones Arqueológicas en España, 16, Madrid-Málaga, 84 p.

PELLICER, M., 1964: El Neolítico y el Bronce de la Cueva de la Carigüela de Piñar (Granada). Trabajos de Prehistoria, $\mathrm{XV}$, Madrid, $71 \mathrm{p}$. 
PERLES, C. y VAUGHAN, P., 1983: «Pièces lustrés, travail des plantes et moissons à Franchthi (Grèce) (Xème-IVème mill. B. C.)». Travaux de la Maison de l'Orient, 5, pp. 209-224.

RODRIGUEZ, G., 1979: «La cueva del Nacimiento (Pontones, Jaén)». Papeles del Laboratorio de Arqueología de ValenciaSaguntum, 14, pp. 33-38.

ROY, S., 1983: «Traces d'utilisation sur des outils a posteriori de Mureybet (Syrie): méthodes d'étude». Travaux de la Maison de l'Orient, 5, pp. 25-29.

ROZOY, J.-G., 1978: Les derniers chasseurs. Bulletin de la Société Archéologique Champenoise, número spécial juin, 3 tomos, Reims, $1.255 \mathrm{p}$.

SAN VALERO, J. 1950: La Cueva de la Sarsa (Bocairente, Valencia). Trabajos varios del Servicio de Investigación Prehistórica, n. ${ }^{\circ} 12$, Valencia, $102 \mathrm{p}$.
SARRION, I., 1980: «Valdecuevas. Estación Meso-Neolítica en la sierra de Cazorla (Jaén)». Papeles del Laboratorio de Arqueología de Valencia-Saguntum, 15, pp. 23-56.

SOLER, J.-M., 1961: «La Casa de Lara de Villena (Alicante). Poblado de llanura con cerámica cardial». Saitabi, XI, pp. 193-200.

SOLER, J.-M., 1965: «El Arenal de la Virgen y el Neolítico cardial de la comarca villenense». Revista Villena, 11.

TIXIER, J., 1963: Typologie de l'Epipaléolithique du Maghreb. Arts et Métiers Graphiques, París, 212 p.

VICENT, A.-M. y MUÑOZ, A.-M., 1973: Segunda campaña de excavaciones. La Cueva de los Murciélagos, Zuheros (Córdoba), 1969. Excavaciones Arqueológicas en España, 77. Madrid, $118 \mathrm{p}$. 